\title{
LA INSURGENCIA NEGRA EN LA ISLA DE CUBA EN LA PRIMERA MITAD DEL SIGLO XIX
}

\author{
POR \\ ALAIN YACOU \\ Université des Antilles et de la Guyane \\ Pointe-à-Pitre
}

Un sinnúmero de sublevaciones de esclavos estallan en la isla de Cuba durante la primera mitad del siglo XIX, fundamentalmente en el período que va de 1795 a 1844. Asimismo, entre 1814 y 1852, tiene lugar la larga guerra de los cimarrones -la palabra no es demasiado fuerte si con ella nos referimos a los acontecimientos producidos más particularmente en la región oriental de la gran isla durante el período indicado. Por la misma época, el movimiento reivindicativo de los negros libres pasa de las intrascendentes manifestaciones de antes a los primeros signos de inconformidad, prometedores de conflictos armados y a las primeras conspiraciones que cuestionan el orden colonial (1).

El objeto del presente estudio se centra en definir cuáles fueron el programa político-social y el contenido ideológico de la insurgencia negra dentro de los límites cronológicos y temáticos propuestos, sin perderse de vista el problema metodológico ya clásico que plantea "la historia de la gente sin historia" para hablar como el historiador cubano Pedro Deschamps Chapeaux. Por lo tanto, al considerarse en su conjunto los distintos movimientos subversivos o antiesclavistas, pueden distinguirse, durante el largo período enfocado, dos fases de una duración aproximada de veinte años:

SigLAS UTILIZADAS:

AGI: Archivo General de Indias, Sevilla.

AHN: Archivo Histórico Nacional, Madrid.

ANC: Archivo Nacional de Cuba, La Habana.

(1) Para una cronología de dichos movimientos, remitimos a J. L. Franco, "Esquema de los movimientos populares de liberación nacional (1511-1868), en Ensayos históricos, La Habana, 1974, págs. 20-32. 
- 1795-1815: fase de iniciación de las masas oprimidas a la ideología revolucionaria libertaria, la cual conllevaba una genuina mística de la redención del negro originada por la revolución de Haití.

- 1820-1844: fase de asimilación y de maduración marcada por la vulgarización eficiente de la ideología abolicionista en un contexto que.es el de la internacionalización del problema negro cubano.

\section{FASE DE INICIACIÓN}

La primera fase abarca una época de sensibilización, de resonancias y de contagio. En efecto, durante esta primera fase, los levantamientos de esclavos corresponden a unos estímulos situados en el exterior de la isla: el formidable impacto de la revolución de Saint-Domingue (Haití) es aquí manifiesto y su influencia duradera. Numerosos testimonios demuestran lo dicho: "desde la desgracia de la revolución de Santo Domingo, recibió un choque el orden colonial", afirmaban todavía en la fecha tardía de 1829 los miembros de la municipalidad de La Habana (2).

De hecho, a pesar de las medidas sanitarias adoptadas por la administración colonial de acuerdo con la plantocracia cubana para preservar a la gran isla contra el incendio, como se decía, de Saint-Domingue, resulta que las masas esclavas, la gente de color en general, no tardaron en percatarse de la trascendencia de los acontecimientos ocurridos en la isla vecina (3). Así es como la idea de imitar la rebelión de los esclavos de SaintDomingue vino a obsesionar la mente de los llamados pardos y morenos de Cuba, desde los primeros momentos. No es por tanto de extrañar que, durante los últimos años del siglo XVIII, una ola de rebeliones haya atravesado toda la extensión del territorio cubano, desde Bayamo, en el umbral de las altas tierras orientales, hasta Mariel, al oeste de La Habana.

(2) AHN, Estado leg. 8.033, "El Ayuntamiento de la Habana..." 4 de noviembre de 1829.

(3) Alain Yacou, "Revolution française dans liile de Cuba et contre-révolution", en De la Révolution française aux révolutions créoles et nègres (s. d. Alain Yacou), París, 1989, págs. 15-40. 


\section{Revueltas de tipo nuevo}

Sin embargo, hay que decir que para este período, no todas las revueltas - de esclavos de las cuales se conserva una documentación notable- presentan un trasfondo ideológico innegable. Bastaría con recordar, a título de ejemplo, el alzamiento ocurrido en el ingenio de azúcar, corral de Santa Cruz, de Don Antonio Ponce de León, el 2 de febrero de 1799. Alli los esclavos se habían amotinado reclamando la vuelta del buen amo que se había ausentado para cumplir con sus obligaciones oficiales en La Habana (4). Hubo muchos casos semejantes, lo que muestra a las claras cómo las revueltas rutinarias contra los malos tratos de los mayorales seguian funcionando como verdaderas válvulas de seguridad del sistema en medio de levantamientos de tipo nuevo (5).

Dichos levantamientos son los que estallan en el centro de la isla, en especial en la zona de Trinidad en 1798 o dos años antes, en la de Puerto Príncipe y en la de Santa Cruz del Sur. En esta última localidad, el amo Don Serapio Recios, que se hallaba ausente de su hacienda y que acudió a ella al conocer la noticia del sublevamiento de la dotación, fue acogido furiosamente por sus esclavos a cuya cabeza se encontraba un tal Romualdo según la relación que se ha conservado del episodio:

Este [Romualdo], desenvainado su machete, le dijo que si pensaba maltratarlo, se engañaba, que todos eran iguales y que verían muy breve los blancos cómo habían de tratar a los negros; acabando su discurso con atrevidas expresiones contra su dueño (6).

Al darse cuenta de la gravedad de la situación, las autoridades locales debieron actuar con el mayor rigor para sofocar este conato de insurrección cuyo carácter político era evidente y que amenazaba ya con arrasar toda la región central de la isla, de acuerdo con los testimonios más fiables: "es un caso nuevo y directamente contra el Estado" dictaminaba el gobernador que

(4) AGI, Ultramar leg. 312, "Movimiento de negros en el Yngenio de Dn. Anto Ponce de León..."

(5) AGI, Ultramar, leg. 312, "Insubordinación de esclavos en algunos Yngenios de fabricar azúcar de esta jurisdicción...", Habana, 20 de abril de 1799.

(6) Ibid., "Relaciones de los varios movimientos de negros acaecidos en la Villa de Puerto del Príncipe y en la ciudad de Trinidad de esta Ysla". 
estimaba necesario un castigo inmediato y ejemplar para los reos, en vez de los lentos procedimientos de la Audiencia de Santo Domingo (7). Estos propósitos, por lo menos excesivos, traducían el temor que experimentaban las autoridades coloniales ante la eventualidad de que los ideales subversivos franceses prendiesen entre las masas de color de la isla. Interesa hacer notar de paso que, dos años antes, la Convención francesa había decretado, como es sabido, la abolición de la esclavitud en las posesiones galas del Caribe ratificando por lo mismo las proclamaciones de libertad general de los esclavos que, impulsados por la necesidad, los comisarios franceses habían adoptado en la colonia de Saint-Domingue. Así que, conocedores de la promulgación de la «ley de los franceses" y propiamente alucinados por el lema de «libertad e igualdad", los esclavos de las demás colonias se sublevaban por doquier (8).

En esta óptica cabe subrayar como en la zona de Puerto Príncipe de Cuba está probado que los llamados «negros franceses" que habían sido traídos a Cuba por sus amos refugiados de Saint-Domingue, se habían constituido en propagandistas acérrimos de las ideas libertarias. Es más, varios de ellos aparecieron involucrados en las sublevaciones que tuvieron lugar, desempeñando el papel de cabecillas u organizadores de las mismas. Por lo demás, parece ser que la estrategia que ostentaban los sublevados, tanto en Trinidad como en Puerto Príncipe, se limitaba a la imitación de los hechos ocurridos en agosto de 1791 en la "Plaine du Nord" alrededor del "Cap Français" en Saint-Domingue que fue, como se sabe, la cuna de la independencia haitiana. Así, pues, confesaron los dirigentes su deseo de hacerse dueños del país mediante una denodada acción de guerra, aleccionados por las noticias cada día más prometedoras que procedían de la isla vecina en que estaba echando las bases de su poder el general Toussaint-Louverture, según la información suministrada por el capitán general de la isla de Cuba (9).

A este primer impulso libertador que corresponde con la fase militar de la revolución de Saint-Domingue (1791-1804) y que por contagio o mimetismo proporcionó conceptos movilizadores

(7) Ibid., id.

(8) F. BRITO Figueroa, Las Insurreciones de los esclavos negros en la sociedad venezolana, Caracas, 1961, págs. 66-67; J. ANDREA OCAÑIz, "La rebelión de los negros de Boca de Nigua", en Anuario de Estudios Americanos, vol. XXVII, Sevilla 1970, págs. 580 y ss.

(9) AGI, Ultramar, leg. 312, "Noticias acaecidas en la Villa de Puerto Príncipe el día 12 de junio de $1798^{\circ}$. 
a las masas esclavas de Cuba, hay que añadir otro que tuvo su origen en la propia coyuntura política hispánica, cuando la invasión napoleónica de la península suscitó, al menos a partir de 1808, trastornos importantes e incluso procesos irremisibles, como se sabe, en el ámbito colonial español.

A este respecto, parece que la historiografía cubana clásica, tan sólo atenta a la vida y hechos de los revolucionarios criollos blancos no se haya dedicado al cumplido estudio de los movimientos populares de aquella época. Es así como, en nuestra opinión, no han sido debidamente valorados los movimientos sediciosos que estallan en marzo de 1809 en La Habana y continúan todo el mes de abril en la extensa zona de plantaciones de la Vuelta Abajo, en especial en las localidades de Cayajabos, Guanajay, San Andrés, San Marcos, Alquízar, donde se hallaban opulentos cafetales pertenecientes a hacendados franceses de Saint-Domingue y de Luisiana refugiados en Cuba.

Estos acontecimientos se han tachado de movimientos antifranceses suponiendo que el populacho tan sólo había arremetido contra dichos refugiados franceses por haber sido fanatizado por las proclamas de las autoridades y las tajantes sentencias de las juntas de vigilancia. Lo que no se dice es que al extenderse a la zona de plantaciones al oeste y al sur de La Habana dichos movimientos habian cobrado repentinamente los caracteres de una lucha popular contra las clases pudientes. Ya no son exactamente los sentimientos patrióticos los que guían a los amotinados cuya fisionomía nos es descrita bajo la pluma de los informadores por los vocablos: "facción de negros, chinos, mulatos y muchachos» o "gavilla de hombres atumultuados». Una orientación social todavía confusa empieza a despertar durante el motín ya que los facciosos saquearon indistintamente las haciendas de los franceses y de los hispano-cubanos. En estas circunstancias no podemos descartar en absoluto que este estado de agitación prolongada haya sido aprovechado por personajes próximos a la ideología revolucionaria. En definitiva, al asalto de los grupos dominantes se encuentra en aquel entonces todo un proletariado, o mejor dicho un lumpen proletariado - «la turba multa» para hablar como los representantes de la autoridad-cuya emotividad y disponibilidad no iban a escapar a la observación perspicaz de los primerísimos dirigentes del independentismo cubano; Francisco Luis Bassave, en particular, quien al año siguiente no dudó en reclutar a sus seguidores en los barrios extramuros de $\mathrm{La}$ 
Habana, donde eran numerosos los libres de color cuando no los cimarrones urbanos (10).

El afan de ver bajo una sola luz lo acontecido en aquellos meses de marzo y abril de 1809 restó fuerzas a la perspicacia de los que han estudiado el carácter de los episodios que venimos examinando. A este respecto, cabe señalar que los excesos de la multitud no se limitaron a saqueos y depredaciones de toda clase. En todas partes fue burlada la rigurosa disciplina de las plantaciones: bajo los ojos de sus esclavos algunos propietarios fueron perseguidos por los amotinados. En una palabra, el orden social estuvo vacilando en una parte considerable del territorio occidental de la isla que resultaba ser uno de los polos de crecimiento de la economía de plantación. En fecha de 23 de marzo de 1809 una carta pletórica de rencor que el hacendado Manuel Abreu dirige al capitán general describe con patético realismo la situación en el distrito de San Marcos:

El desorden y falta de respeto a las autoridades, con que se conducen algunos vecinos [escribía él] me mueven a hacer presente a vuestra señoría que no hay cafetal que no haya sido saqueado, bajo el pretexto de expulsar a los franceses, ni individuos de aquella nación que no haya sido insultado y atropellado. Este manejo a la vista de nuestros negros puede traer consecuencias funestas, si en tiempo no se sofoca (11).

El carácter antiesclavista del movimiento insurreccional también aparece en otros casos semejantes. Es de notar cómo, en la fecha de 14 de marzo, el influyente marqués de Cárdenas había lamentado el inmejorable ejemplo de los esclavos del cafetal del marqués de Espinville, rico emigrado francés: éstos, después de haberse declarado libres, "han expuesto con la mayor audacia y resolución que en el caso de volver a ser gobernados por su amo u otro francés le quitarían la vida" (12). En suma, las semillas del precoz abolicionismo francés que habían encontrado un terreno abonado en la colonia de Saint-Domingue, germinaban ya en la gran isla ayudadas por la crisis española del siglo pasado. No en vano, en otra carta de 25 de abril de 1809, el hacendado Abreu increpaba otra vez la asombrosa irresponsabilidad de los que, en La Habana, habían provocado aquellos disturbios «de que podían

(10) J. L. Franco, Las conspiraciones de 1810-1812, La Habana, 1977, pág. 10.

(11) Véase A. Yacou, L'émigration à Cuba des colons français de SaintDomingue au cours de la Révolution, Burdeos 1975, vol. IV, pág. 504.

(12) Ibidem. 
resultar las funestas consecuencias que eran de esperar de las ideas de libertad que iban sembrando en los esclavos».

\section{La amenaza de los cimarrones}

Por todo ello, no es aventurado afirmar que, al alborear el siglo XIX, la iniciación sui generis de las masas negras a los ideales revolucionarios se había cumplido en la isla de Cuba. Los hacendados criollos más preeminentes que, a la sazón, eran los más fieles aliados de los administradores españoles frente al peligro negro estaban intimamente convencidos de ello (13). Sin embargo no fueron las incipientes sublevaciones de las dotaciones de los cafetales e ingenios lo que más alertó a la plantocracia cubana sino la constitución de palenques de cimarrones en la extensión montañosa del territorio. Fue ésto otro foco de inquietud lo que determinó la puesta en marcha de un sistema de represión ideado por el que fue el oráculo de la sacarocracia, Francisco de Arango y Parreño, durante la reunión de la junta de gobierno del Real Consulado, el 10 de abril de 1796. Estaba fresca, en aquel entonces, en las mentes de todos la memoria de la guerra de los cimarrones ocurrida en la isla vecina de Jamaica y durante todo el período que nos ocupa mucho se temía la creación de un gran palenque "semejante al que toda la eficacia de los ingleses no (había) podido destruir (...) por no haber tomado a tiempo oportuno las medidas correspondientes" según escribía en 1819 el capitán del partido de Cayajabos (14).

Por lo tanto, el cimarronaje siempre fue interpretado por los mas autorizados exponentes de los grupos dominantes como una amenaza inminente contra la economía de plantación y un fermento de disolución de la sociedad esclavista. Para ellos, el esclavo fugitivo se había hecho el enemigo del género humano, "de los demás hombres civilizados y cristianos»:

La criminalidad pues, con que se supone a los cimarrones para haberlos comprehendido en los casos de Hermandad está demasiado indicada en el hecho de su fuga, su desamparo por los dueños, y en sus empresas feroces,

(13) S. Aguirre, "Esclavitud y abolicionismo", in Eco de caminos, La Habana, 1974, págs. 97 y ss.

(14) ANC, Real Consulado, leg. 141, ne 6.934. Expediente 1.099 sobre la destrucción de palenques en las sierras de la Vuelta de Abajo. 
aseveraba al respecto en 1797 don Juan Zequeira y Palomar, alcalde mayor provincial de la Santa Hermandad de la ciudad de La Habana (15). Asimismo el informe del otro alcalde nos proporciona, en la misma época, aunque de manera indirecta, un valioso testimonio sobre la voluntad de ruptura radical con el mundo colonial esclavista que animaba a los cimarrones:

Se inflama su ignorancia con el espíritu de independencia que gozan. Se consideran señores de los brutos, de las fieras y de las aves y ya se figuran que no deben subordinarse a los demás hombres. Saben que los blancos los compraron en los almacenes y sólo por esta razón los miran como enemigos capitales y guardan en el fondo de sus corazones una ira implacable con que los exterminarían si estuviese en su arbitrio (16).

Es interesante notar cómo algunos años más tarde los alcaldes de la Santa Hermandad de Santiago de Cuba no dudaban en definir a los cimarrones como «malvados que atacan el orden social» (17). No era excesivo este punto de vista: no faltaban en efecto motivos de alarma en la región oriental de la isla a cuyos montes huían numerosos esclavos procedentes de los cafetales que pertenecían a los refugiados franceses radicados en esta región. Todo indicaba que se estaba preparando una verdadera guerra social: la existencia del gran palenque denominado $E l$ Frijol hacía legítimas las inquietudes de los administradores y de los hacendados santiagueros. De hecho, menos de tres años después, estalla en el Oriente cubano la larga guerra de los cimarrones que incluso puso en peligro, durante su primera fase, a la ciudad de Santiago de Cuba (18).

Así pues, a comienzos del siglo XIX y sobre todo en el marco de la región oriental el cimarronaje rural se identificaba con un proyecto de subversión de la sociedad colonial. No obstante debemos decir en justicia que no tenemos para este período inicial pruebas irrebatibles de todo ello. Aun cuando la acción entablada por los cimarrones, que amenazaban con arrasar el cinturón de cafetales que rodeaba a Santiago de Cuba, conllevaba

(15) AGI, Estado $8 n^{0}$ 4, Doc. i, no 16, "representación elevada a S. M. por Dn. Juan de Zeiqueira y Palomar... 2 de mayo de 1797".

(16) Ibid., n 18, Havana 2 de mayo de 1797.

(17) "Representación formada por los Alcaldes de la Santa Hermandad" en Z. Danger Roll, Los cimarrones de El Frijol, Santiago de Cuba, 1977, p. 89 y ss.

(18) A. YACOU, Le problème noir et son expression dans la litterature à Cuba, dans la première moitié du XIXo siècle (tesis de doctorado), Burdeos, 1981, vol. 2, págs. 624 y ss. 
por lo mismo un discurso político implícito, todo lo que sabemos acerca de lo acontecido es el fruto de las declaraciones alarmistas de los hacendados esclavistas y de sus aliados, los administradores civiles y militares, lo que, por ende, no autoriza sacar conclusiones definitivas sobre el particular.

\section{La conspiración de Aponte}

Sea lo que fuere, es durante este período de tensiones, de inquietudes e incluso de enfrentamientos esporádicos, cuando se fragua la conspiración de José Antonio Aponte cuya trascendencia no habría escapado a la observación de los representantes del poder colonial: «Esta fue la principal especie con que se procuró trastornar la antigua y bien acreditada sumisión de los siervos" apuntaba al respecto el capitán general de la isla, Someruelos (19).

No es nuestro propósito insistir en los rasgos de la brillante personalidad del líder, admirablemente descritos por su mejor biógrafo, José Luciano Franco y menos aún recalcar sus dotes excepcionales de organizador revolucionario ensalzados por Elías Entralgo (20). Quisiéramos solamente aventurar unas puntualizaciones sobre las finalidades esenciales de dicha conspiración que, a pesar de su fracaso, constituye a nuestro parecer un ensayo insólito en la medida en que se inaugura, en una forma todavía rudimentaria y bajo la dirección de un negro libre, este tipo de revolución a la vez anticolonial y antiesclavista que a la larga triunfará en la isla de Cuba. Por lo mismo disentimos de la opinión del insigne historiador Vidal Morales y Morales, quien, en su tiempo, aseveró que «el negro José Antonio Aponte dirigía aparentemente la conspiración" y que "en realidad era un instrumento de los blancos que en ella estaban comprometidos» (21).

Por cierto, la conspiración de Aponte se había desvinculado de las primerísimas intentonas criollas de aquella época y en especial de la que capitaneaba Francisco Luis Bassave en 1809 . 1810 , que tenía por objeto una mera independencia política sin ningún tipo de descolonización social según se desprende del texto fundamental redactado por el abogado Joaquín Infante y

(19) ANC, Asuntos Politicos, leg. 12, n²4, Bando del Capitán General de la isla (...) lecha Habana, 7 de abril de 1812 .

(20) J. L. Franco, La conspiración de Aponte, La Habana, 1963 y Elias EnTralco, La liberación élnica del cubano, La Habana, 1953, pág. 24.

(21) V. MORALlis y MORALES, Iniciadores y primeros márlires de la revolución cubana, Consejo Nacional cle Cultura, La Habana, 1963, pág. 249. 
titulado Proyecto de Constitución para la isla de Cuba (1811)(22). Por el contrario, Aponte que bien conocía los límites del programa de los rebeldes criollos de principios del siglo, quería superarlos.

Cabe señalar por otra parte que la conspiración de Aponte tampoco era un movimiento de libertos cuya meta sólo hubiera sido conseguir la igualdad con los blancos: muy bien sabían el líder y sus seguidores que tal igualdad no podía lograrse dentro de los moldes de una sociedad esclavista cualquiera que fuese. Por ello es por lo que la conspiración de Aponte se diferencia de la que dirige aparentemente, en 1795, otro libre de color, el mulato Nicolás Morales en la región de Bayamo (23). Por sus objetivos, esta última tiene que ver mucho con la del malogrado mulato francés Ogé en Saint-Domingue que luchó por la aplicación de los decretos igualitarios promulgados por la asamblea legislativa francesa. En ambos casos se trataba de una mera reforma de la sociedad colonial esclavista, que de ningún modo entrañaba la destrucción de los fundamentos todos de la misma (24).

A la inversa, Aponte y sus partidarios adoptaron una posición radical al tratar de transformar la lucha secular de los esclavos por la libertad en una lucha contra el mismo sistema esclavista. Una circunstancia inesperada, es cierto, no tardó en legitimar la propaganda de los conspiradores que buscaban hacer prosélitos entre los numerosos negros libres y esclavos que vivían en los barrios extramuros de La Habana: se trataba de la noticia según la cual se había leído un proyecto de abolición de la esclavitud en una de las sesiones de las Cortes de Cádiz. Además de ello los constituyentes españoles, o por lo menos los exponentes de las ideas liberales, habían planteado la necesidad de dejar abiertas las carreras eclesiásticas o universitarias a «los súbditos españoles que por cualquier línea tienen su origen de African (25). No se ignora cómo estos conceptos provocaron la ira de los miembros

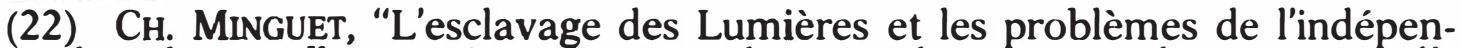
dence dans les Antilles (1810-1820), en Mélanges à la memoire de Jean Sarrailh, Paris, 1966, tome II, págs. 177-192, y Eric NABAJOTH, "La constitution d'Infante: les avatars de la philosophie des Lumières a Cuba", en De la Révolution française, [3] págs. 185-194.

(23) Franco, "La conspiración de Morales", in [1] pp. 93 y ss.

(24) Y. DebBasch, Couleur et liberté, le jeu des criteres ethniques dans un ordre juridique esclavegiste, Paris, 1957, tome I, pág. 118.

(25) Acerca de los supuestos y limitaciones de los debates y de las decisiones en el particular, remitimos a M. L. RiEu-MillaN, "Les Cortés de Cadix et leurs députes d'outre-mer face au modèle français de révolution politique", in Les Révolutions Ibériques et Ibéro-Américaines à l'aube du XIXo siècle Paris, 1991, págs. 155-158: la liberté et l'égalité. 
principales de la sacarocracia habanera, que comisionaron a su mejor ideólogo Francisco de Arango y Parreño «para que redactara un alegato minucioso y enérgico contra toda alteración en el régimen esclavista que presidía en Cuba» (26).

Así, mientras cundía la alarma entre la élite ilustrada y adinerada, Aponte y los suyos hicieron circular la flamante noticia que, como puede suponerse, tuvo fácil acogida dentro de un determinado estrato social. En otros términos el contexto social y la coyuntura política se compaginaron para concederle a Aponte las atribuciones de este Espartaco o Moisés negro cuya emergencia había sido vaticinada por el insigne abate Raynal. Fue el historiador Elías Entralgo quien acertó a percibir este acendrado mesianismo que caracterizaba a la acción de Aponte:

Estaba dotado de una mentalidad que podriamos llamar geométrica. El tenía un exacto conocimiento de la verdadera situación intelectual y cultural de los que continuaban bajo la esclavitud; y, en consonancia con la misma, utilizó los argumentos más convenientes y oportunos -quién sabe si los únicos posibles - para ganarse la volición; -ipor tantos lados admirable! - de aquellos seres humanos cuya vida era una perenne asfixia espiritual (27).

De hecho, parece ser que el objetivo supremo de la conspiración se inspiraba en la mística de la redención del negro. Esta trascendental meta se trasluce en el material propagandístico que Aponte había almacenado en su propia casa. En ella, en efecto, la policía había encontrado, entre los documentos y libros que se le había incautado, un voluminoso registro en que aparecían varias estampas o láminas de ilustres personajes negros de la Antigüedad o de los tiempos bíblicos: príncipes, militares 0 eclesiásticos (28). Por una parte, eran pinturas ejecutadas por el mismo Aponte y por otra, grabados alusivos recortados de libros que el líder había adquirido con paciencia y sabiduría. Se trataba,

(26) Obras de Don Francisco de Arango y Parreño, Publicaciones de la Dirección de Cultura del Ministerio de Educación, La Habana, 1952, t. II págs. 145-187.

(27) Entralgo, [20] pág. 25.

(28) Al decir de Aponte, estos personajes eran, según se lee en el expediente: “Abalseo, primer apóstol moreno ordenado por el propio San Felipe...La reyna Candase de Avicinia (sic)... Los príncipes de Avicinia... Los tres Reyes Magos... Un cardenal y otro religioso de la Orden de San Benito, ambos morenos, el primero nombrado Jacobo y el segundo sin nombre y bibliotecario de su Santidad... El rey Tarraco que tomó a Tarragona (...) y sus tropas cuyas insignias de banderas amarillas y leones negros con cruz encarnada son las que usan los de Abicinia", en AHN, Asuntos Políticos, leg. 12, n 17. 
pues, de una cumplida obra de propaganda hábilmente elaborada - un manifiesto de la negritud avant la lettre, permítasenos llamarlo así- y que el jefe de la conspiración utilizaba con acierto para aleccionar a sus prosélitos y convencer a los más incrédulos de la necesidad de restituir a los negros sus preeminencias anteriores y poner término al menos a los excesos de que eran víctimas en la sociedad colonial.

Sin embargo para llevar a bien su labor conspiradora, Aponte no contaba únicamente con la ejemplaridad de estos anticuados personajes. La revolución negra de Saint-Domingue ofrecía, desde luego, ejemplos todavía más fehacientes de una posible ascensión del negro. En 1812 ningún hombre de color, como se decía, a menos de ser bozal, recién llegado a las Antillas, ignoraba la existencia en ellas de este verdadero refugio que constituía entonces la nación haitiana tal como lo habían proclamado sus propios gobernantes (29). El consabido proselitismo haitiano, inaugurado por el mismo Toussaint-Louverture en su tiempo, tenía ya aceptación entre las masas de color de la isla de Cuba. Prueba de ello, se encontraban en la casa de Aponte cuatro retratos de los conocidos dirigentes Jean François, Toussaint-Louverture, Dessalines y el rey Cristóbal. Dichos cuadros formaban parte de los medios de propaganda de que se valía Aponte para producir tomas de conciencia entre sus correligionarios a los que hizo creer que le habían sido enviados por los mismos gobernantes haitianos (30). Es más, aprovechándose de la estancia en La Habana, en 1812, del general negro Gil Narciso - que por cierto, como Biassou o Jean François, mandaba en el ejército auxiliar español en la isla de Santo Domingo cuando el conflicto con Francia-Aponte dejó entender a los suyos que se trataba de un emisario del rey Cristóbal, "un enviado de toda su confianza para promover el levantamiento y cuanto fuese necesario» (31). Se sabe que, al volver a su tierra, el mencionado general de cuyas intenciones poco supieron los jueces en La Habana, no tardó en formar parte de una conspiración fomentada por tres negros libres cuyo objeto wera la libertad de su raza y adherirse a la República de Haití» (32).

No obstante, sería aventurado dejar sentado que la conspira-

(29) P. Verna, Bolivar y Petion, Col. Bicentenario de Simón Bolívar, no 1, Caracas, 1980, pág. 50.

(30) ANC, Asuntos Políticos, leg. $12 \mathrm{n}^{\mathrm{Q}}$ 17, Declaración de José Melchor Chirinos. 26 de marzo de 1812.

(31) Ibid: Informe del Fiscal Dr. Rafael Rodríguez sobre la averiguación de los cómplices en la conspiración de los negros...".

(32) Franklin J. Franco, Los negros, los mulatos y la nación dominicana, Santo Domingo, 1970 (5. Edición), pág. 119. 
ción de Aponte se asemejaba a la vía haitiana de la revolución: tanto el contexto social como la realidad etno-demográfica de la isla no lo hubiera permitido. Al revés, por el contenido ideológico y el programa social de su movimiento, Aponte trató de elaborar una plataforma política multiracial contra la opresión colonial. Se nos impone aquí la conclusión de Elías Entralgo: «Pero lo más admirable de esa conspiración fue su poder conglutinante. Logró que cesaran las pugnas entre las varias sub-razas africanas, pugnas atizadas en la superficie por los contramayorales... Confundió a los negros esclavos con los libres. Acercó los mulatos a los negros. Sacó de sus casillas a los chinos, contó con los blancos como dirigidos y como dirigentes" (33).

\section{FASE DE MADURACIÓN}

En la segunda fase de las rebeliones negras - fase de maduración- las orientaciones ideológicas que se habían diseñado en la primera fase se confirman o se precisan. Más allá del proceso de contagio haitiano vemos perfilarse los objetivos de un proyecto realmente sedicioso en los tres niveles señalados de la insurgencia negra.

\section{La reanudación de la guerra de los cimarrones}

La toma del gran palenque El Frijol había puesto término en 1816 a la ofensiva de los cimarrones de la región oriental que se habían lanzado a cometer asaltos contra los cafetales que rodeaban la ciudad de Santiago de Cuba, con muerte de mayorales, raptos de esclavos e incendios de fábricas (34). Pero contra los irreductibles apalencados que poblaban todas las sierras de la isla, hacía falta una persecución permanente destinada a contener en un primer tiempo las incursiones de los más atrevidos y después llevar la guerra hasta sus refugios. Con esta mira se ordenó una movilización general y se puso en actividad a la tropa veterana y a las milicias, así como las cuadrillas de rancheadores más famosos. En estas condiciones las hostilidades volvieron a romperse entre los apalencados y las fuerzas de

(33) Entralco, en obra citada en nota [20], pág. 27. Frijol.

(34) ANC. Asuntos Políticos, leg. 109, N. 34 (varias cartas sobre la toma de El 
represión en toda la extensión de la isla y más particularmente en las sierras orientales, donde se reanudó la larga guerra de los cimarrones que no cesó hasta el año 1852. Conviene, pues, preguntarnos a la vez sobre los ideales y estrategias que conformaban la constitución de las sociedades cimarronas y los objetivos y móviles que entrañaba la contraofensiva de los cimarrones suscitada por la destrucción del más famoso de sus refugios.

En términos generales se puede aducir que por su misma conformación, o por el mero espacio que ocupaban, las sociedades cimarronas, para hablar como Roger Bastide, tenían que chocar con los núcleos colonizadores y los polos de crecimiento de la economía de plantación ya que el desenvolvimiento de aquéllas debilitaba la integridad de éstos y viceversa. La impresión de conjunto que se desprende del análisis de los valiosos documentos que acerca del cimarronaje rural se conservan en el Archivo Nacional de Cuba es que dicho cimarronaje constituyó por su sola existencia un factor importante de superación del orden colonial. De manera aún más inconfundible que en las demás colonias antillanas, los palenques cubanos ofrecieron en numerosos casos un asilo seguro a los esclavos fugitivos: eran aquellos palenques - sobre todo los de Oriente- una base de resistencia colectiva a la vez militar, económica, social y cultural a la opresión esclavista.

Sin embargo si se quiere evitar generalizaciones exageradas en estos planteamientos, se debe tener en cuenta que desde el punto de vista cultural las cimarronadas no dieron paso a un retorno a Africa (35). La modernidad, o si se quiere la americanidad del proceso, resulta ser franca e inconmovible en aquel período. En efecto, nos interesa hacer constar en primer lugar que las sociedades cimarronas ya no son en absoluto tentativas de reagrupamiento de individuos procedentes de una misma nación africana. Aquí se produce una solidaridad que supera la división étnica, una solidaridad nueva configurada por el sentido de pertenencia a una comunidad supranacional: en el palenque, aseveraba Elías Entralgo, ya surge el ánimo de solidaridad social (36). En términos antropológicos puede decirse que existió una etnicidad cimarrona (37). De hecho el sincretismo cultural

(35) Y. DebBasch, "Le marronnage: essai sur la désertion de l'esclave antillais", 1. a parte, en L'annee sociologique, 1961, pág. 96, y G. DEBIEN, Les esclaves aux Antilles Françaises Basse-Terre/Fort-de-France, 1974, pág. 421.

(36) ENTRALGO, [20], pág. 8.

(37) B. Kopytoff, "Le developpment de l'identité ethnique chez les marrons de la Jamaique", in Esclave = facteur de production, Paris, 1981, pág. 119. 
entre las etnias o naciones africanas esbozado en el marco de las plantaciones, se continúa en el cimarronaje rural y no se altera por ende la transculturación del bozal. No podía ser de otro modo ya que negros criollos y a veces mulatos libres convivían con africanos en los palenques. De ahí cierta heterogeneidad estructural de las sociedades cimarronas, pese a los aportes renovados de los negros de trata. Más aún, se señala en varios casos la presencia de hombres blancos en los palenques: se trataba de refractarios al servicio de la milicia, contrabandistas o comerciantes al por menor, en especial catalanes e, incluso, eclesiásticos que, llegado el caso, celebraban misas y confesaban a feligreses cimarrones como sucedía en el gran palenque Todos Tenemos en que sus moradores habían edificado una iglesia, o mejor dicho una capilla dedicada a un santo de la religión católica (38). Todo ello nos impele a concluir que las comunidades cimarronas seguían en contacto estrecho con las sociedades de plantación: los numerosos intercambios entre estos dos mundos constituyeron un factor determinante de una neoculturación del fugitivo, al decir de F. Ortiz, siendo el cimarronaje, por ende, la vía libre de adaptación del africano al nuevo mundo (39).

Desde luego no fue la convivencia lo que mayormente reguló el tipo de relaciones entre los palenques de cimarrones y las haciendas esclavistas. Por su modo de producción la sociedad cimarrona fue, al decir del sociólogo haitiano Jean Casimir, una contraplantación. De ello se infiere que la emergencia de dicha sociedad suponía una ruptura radical con la economía de plantación. No obstante, conviene aclarar que tan sólo pueden aplicarse estos conceptos a los palenques de la región oriental de la isla, donde un genuino campesinado cimarrón supo echar las bases de toda una organización económica agropecuaria autosuficiente.

Pero los palenques no representaban tan sólo un cómodo asilo o una oportuna base de resistencia pasiva para los prófugos. Es sumamente significativo que en el gran palenque El Frijol se haya encontrado una forja donde los cimarrones fabricaban lanzas y otras armas ofensivas. Cualquiera que sea la fisionomía del refugio - pueblo fortificado o simple conjunto de bohíos, ranchería provisional y precaria-, cualquiera que sea el paraje donde se ubicaron los palenques - guaridas casi inaccesibles en

(38) ANC, Misceláncas, leg. 4.040, no Ai, carta del sargento Martínez, 11 de diciembre de 1815 .

(39) A. Yacou, "Altérité radicale et convivencia: le marronnage dans l'ile de Cuba dans la premiére moitié du XIXo siècle", Structures et cultures des sociétés ibéroamericaines, Paris, 1990, págs. 107 y ss. 
lo alto de las sierras o aldeas metidas en manglares inhóspitos-, cualquiera que sea el número de los fugitivos - el cual fluctuaba entre 10 y 300 personas- la organización institucional de la sociedad cimarrona es de tipo militar: un sólo jefe, cuyo poder es absoluto. Militarismo y despotismo fueron en toda la América de plantaciones la condición sine qua non de la supervivencia del grupo de prófugos: cualquier cimarrón lo sabía. Por lo tanto los palenques constituian en todas partes una perfecta maquinaria de guerra.

Estas circunstancias bastan para avalar la estimación que del cimarrón ofreció el llorado historiador cubano José Luciano Franco en estos términos: "No era nada más y nada menos que un rebelde, cuya determinación de romper con el estatuto de la opresión se manifiesta en su decisión de defender sus privilegios inalienables de hombre..." (40).

Por supuesto, puede preguntarse si dicho rebelde tuvo siempre una visión tan clara de los actos que asumía. Más aún, interesa saber si la ofensiva generalizada de los cimarrones contra los hatos, cafetales e ingenios que da la tónica al período estudiado, respondía a un plan previo.

En primer lugar no hay que descartar la hipótesis de una real politización de las luchas de los cimarrones. Ya en los años 1820 se sabía que los apalencados de la región occidental recibían armas de fuego de manos de corsarios extranjeros: circulaban en los refugios monedas inglesas. Todo parecía indicar la presencia de agentes «interesados en la destrucción de esta preciosa isla" según escribía el coronel Miranda que patrullaba en la Vuelta Abajo (41). Asimismo, la radicalización del proceso de rebeldía de los cimarrones de la parte oriental de la isla podía explicarse por la presencia misteriosa de emisarios haitianos en los palenques, señalada varias veces por las autoridades locales, al menos entre 1832 y 1841 . Las observaciones del mismo gobernador Pedro Becerro merecen aquí nuestra atención:

Los puntos donde particularmente se reunen los palenques de cimarrones, le decía al capitán general, son las montañas de los alrededores de Santa Catalina, y las que continúan hasta Baracoa como siempre tratan de acercarse a donde se les facilite más su comunicación con Haití, por ser la tendencia de todos

(40) J. L. Franco, Los palenques de los negros cimarrones, La Habana, 1973, págs. 7-8.

(41) ANC, Gobierno Superior Civil, leg. 625, n 19.876, carta del 6 de octubre de 1822 del Coronel Miranda. 
ellos imitar en los campos de acá las atrocidades de los de Santo Domingo (42).

De hecho, en todas partes parece que a los cimarrones les alentaba el proyecto de desorganizar completamente el aparato de producción de las plantaciones. Todavía en la fecha remota de 1852 firmaban una enérgica circular un buen número de hacendados franceses radicados en los alrededores de Santiago de Cuba lamentando los excesos de los cimarrones que «seducían esclavos y robaban negras a la fuerza» (43). Esas inquietudes no carecían de fundamentos. En varios partidos del oeste, la conjunción entre los asaltos a las haciendas y las revueltas de las dotaciones de las mismas eran evidentes, como aclaraba el ya mencionado coronel Miranda en un informe al capitán general de la isla:

Esos sucesos los graduará cada cual según su modo de ver, y quizá los marquen de indiferentes, pero los hombres prácticos en las revoluciones mirarán en ellos los resultados de otros principios, capaces de esparcir una llama devoradora que arruine este edificio social (44).

Oleadas de pánico se produjeron en todos los campos y aldeas que vivían bajo la amenaza permanente de los cimarrones: se afirmaba que "podía peligrar la tranquilidad pública si no se destruía de raíz esta mala semilla que sólo vivía por la impugnidad con que vivía hacía años». Buen testimonio de todo ello es la carta patética que el marqués de Casa Ramos de la Fidelidad dirigió a los miembros del Real Consulado el 9 de abril de 1819:

En el día es más preciso que nunca su exterminio pues si se abandona o se desiste de su persecución crecería su orgullo, se aumentaría infinitamente el número de cimarrones y apenas habría finca de algunas leguas en contorno de la loma que corre desde el Cuzco al cabo de San Antonio que pudiese contar con la fidelidad y asistencia de sus siervos, en cuyo caso sería menos malo abandonarlas y refugiarse con sus esclavos en los llanos (45).

(42) ANC, Asuntos Políticos, leg. 135, no 15, carta del 26 de noviembre de

(43) ANC, Gobierno Superior Civil, leg. 623, n 19.587. Monte Líbano y abril 19 de 1852.

(44) ANC, Gobierno Superior Civil, leg. 625, no 19.876 (vide supra, nota 41).

(45) ANC y Real Consulado, leg. 141, n”6.934, San Marcos 9 de abril de 1820. 
A la luz de tales sucesos es legítimo pensar que los apalencados conocedores del miedo que infundían a los hacendados se han dejado llevar por el anhelo de destruir los símbolos y las estructuras de la explotación de que eran víctimas los esclavos. No obstante es justo hacer constar que todas las estrategias de los cimarrones no se centraban, ni mucho menos, en unos asaltos a las unidades de producción de la economía de plantación, con notorios objetivos de destrucción del propio sistema esclavista. No hace mucho que al terciar en la conocida polémica de Yvan Debbasch con Jean Fouchard acerca de las causas del cimarronaje el historiador dominicano Rubén Silié acertó a decir que los cimarrones se opusieron a la explotación a que se les sometía en tanto que clase en sí, pero sin llegar a hacer planteamientos como clase para sí (46). En otros términos bien pudiera ser que tan sólo fuera la ofensiva generalizada de los cimarrones, la respuesta inexcusable a los avances de los cultivos y al inquietante desmonte que amenazaba su propio espacio. Por otra parte, la técnica de la persecución continua puesta en práctica por los rancheadores, cuando no los militares que restaba fuerzas al desenvolvimiento de sus sociedades cuyo equilibrio demográfico seguía muy frágil, determinó una adecuada reacción de su parte.

Sea lo que fuere, no puede perderse de vista que en una ocasión, durante el período estudiado, los cimarrones pudieron exponer de viva voz el programa que habían elaborado. Esto sucedió cuando tuvieron lugar negociaciones entre los jefes cimarrones - Ventura Sánchez alias Coba y Manuel Griñán alias Gallo- de una auténtica confederación de palenques de la provincia oriental y el gobernador Eusebio Escudero de dicha provincia. Se sabe que "movido por un efecto de compasión a los negros extraviados en los palenques y al ver privada la agricultura de tantos brazos que podían ser útiles al estado», este gobernador había planteado a los miembros de la Real Audiencia la necesidad de una reducción pacífica de los cimarrones, dueños de la extensa zona montañosa que va de Sagra a Baracoa pasando por Guantánamo. Al respecto, solicitaba del tribunal la facultad de perdonar la pena de muerte a los capitanes de los expresados palenques "siempre que éstos se constituyeran a cumplir las órdenes de este gobierno, conduciendo atados los de su partida a gozar de la gracia que el gobierno les tenía preparada para facilitarles en poco tiempo la libertad a todos...» (47).

(46) R. SilıE, Economia, esclavitud y población, Santo Domingo, 1976, pág. 89.

(47) ANC, Asuntos Políticos, leg. 125 n 12: Santiago de Cuba, julio 10 de 1819. 
Por su parte, los jefes cimarrones presentaron al enviado del gobernador sus reivindicaciones esenciales que se resumian en dos palabras: «tierra y libertad». Hicieron entender que no querian a ningún precio y bajo ningún tipo de contrato trabajar para sus antiguos dueños. Solo querían establecerse en sus propias tierras, las que habían desmontado en las sierras, constituyendo por lo mismo un campesinado libre al margen de las plantaciones y disfrutando únicamente de los frutos de su propia industria (48). Como se ve, lo que exigían los cimarrones era la libertad absoluta. Desconfiaban del estatuto de libertos que se les iba a otorgar, sabiendo que bajo ningún concepto pudieran disfrutar de todo lo ofrecido por la sociedad colonial por los efectos de esta «sociabilización incompleta" (en frase de F. H. Cardoso) del negro libre en el mundo colonial esclavista. Por lo tanto, proclamaron su voluntad de vivir de acuerdo con sus propias leyes, fuera del ámbito de dicho mundo. Así que estos aguerridos rebeldes tan sólo deseaban compartir la tierra con los que les habían esclavizado antes. En una palabra, pretendían convivir con la sociedad colonial esclavista a falta de destruirla.

\section{La radicalización de las revueltas}

Una reivindicación de la libertad parecida, aparece como fundamento de las sublevaciones de esclavos que estallan entre 1821 y 1843. Sin embargo, los supuestos y objetivos de dichas sublevaciones eran algo distintos de los que ofrecía la ofensiva de los cimarrones. A este respecto, cabe señalarse de entrada que si la cimarronada tuvo con creces más incidencia en el Oriente cubano, fue en la región occidental de la isla, y más concretamente en la zona azucarera de Matanzas, donde las revueltas de las dotaciones de los ingenios alcanzaron, en 18421843 , su más alto nivel de violencia. El estallido en estos parajes de levantamientos en cadena y de numerosos complots, delatados a tiempo, motivaron que se pensara que los sublevados habían llegado a una fase superior de organización y que se estaba fomentando una insurrección general que pudiera derrocar todo el orden social y colonial.

Por cierto, no se ha dejado de señalar cómo los malos tratos

(48) Ibid, Informe del presbitero Juan Luis Manfugas al gobernador de Santiago de Cuba, "Fecha Sn. Anselmo de Tiguabos, 31 de julio de 1819, sobre el resultado de la visita al palenque mandado por el caudillo negro Ventura Sánchez (a) Coba. 
de todo tipo y los excesos de que, con la mira de mejorar los rendimientos, eran víctimas los esclavos durante la molienda, pudieron determinar revueltas de cierta trascendencia. Pero la contraviolencia de los oprimidos también pudo enmarcarse en un auténtico proyecto antiesclavista más allá de las causas clásicas que se suelen atribuir a las revueltas de los esclavos rurales. A este respecto, convendría saber hasta qué punto la ideología abolicionista, imbuida por agentes extranjeros, tuvo impacto en las masas esclavas (49). $\mathrm{Si}$, con arreglo al cúmulo de pruebas esgrimidas por la sacarocracia cubana se acepta la hipótesis de que hubo una perfecta conjunción entre la ideología abolicionista difundida por los propios funcionarios británicos - como David Turnbull, cónsul que fue en La Habana- y la lucha de los esclavos por la libertad, quedaría por examinarse el contenido que estos últimos atribuían a dicha libertad, que reivindicaban con las armas en las manos, y apreciar el grado de coherencia de su programa libertario.

La tarea no es nada fácil puesto que, como aseveró Cepero Bonilla en su tiempo, siempre se trataron de ocultar los esfuerzos intentados por los esclavos con el objeto de conquistar su libertad y se ha difamado el carácter de sus movimientos de protesta (50). No podía ser de otro modo ya que cada vez que se les planteó el problema negro saltó a la memoria de los dueños de esclavos y de los administradores de la colonia el recuerdo imborrable de la revolución de Saint-Domingue. Así para los esclavistas, como aclaraban los miembros del Tribunal de Comercio de La Habana reunidos en marzo de 1841, el esclavo no podía interpretar la idea de libertad más que de forma apasionada e irracional, o sea peligrosa para el orden establecido (51). En la misma época, echando mano de una sentencia del autor de De la démocratie en Amérique que decía: "partout où les nègres ont été les plus forts, ils ont détruit les blancs», los miembros de una comisión de la Real Junta de Fomento confesaban, por su parte, que, en su opinión, «morir o dominar era la única alternativa que había del blanco al negro...» (52).

En rigor lo que se había dado a llamar guerra de colores no

(49) A. YACOU, "El impacto incierto del abolicionismo inglés y francés en la isla de Cuba (1830-1850), en Esclavitud y derechos humanos, Edición de F. DE SOLANO, CSIC, Madrid, 1990, págs. 456 y ss.

(50) R. CePero Bonilla, Azúcar y abolición, La Habana, 1971, pág. 100.

(51) AHN, Ultramar, leg. 3.550, "A la Regencia Provisional del Reyno", La Habana, marzo 30 de 1841.

(52) ANC, Asuntos Políticos, leg. 231, n. 5, Habana, septiembre 28 de 1841. 
era nada menos que un conflicto de clases: se trataba menos del exterminio de la comunidad blanca que de la destrucción de un sistema por la eliminación radical de los que lo sustentaban. Así lo entendía el "divino" Argüelles, quien en pleno Parlamento español durante el debate de 1836 señaló certeramente la disyuntiva en que se encontraban las masas esclavas de la isla de Cuba:

Alli, Señores, hay una raza que se cree irreconciliable, y que aspira a la destrucción de los demás habitantes, porque no de otra manera espera obtener su libertad (53).

Guerra de colores o guerra de clases: encontramos aquí de nuevo toda la ambigüedad o la complejidad del conflicto entre los esclavos y sus amos en el ámbito colonial. Profundizando esta temática, convendría captar más allá de los planteamientos de los esclavistas las orientaciones fundamentales de las rebeliones de esclavos. Así, para tomar un ejemplo significativo, a los jueces que trataban de sondear sus intenciones los dirigentes, algo exaltados por cierto, de una sublevación ocurrida en la localidad de Limonar cerca de Matanzas, en 1826, indicaron con estos términos el programa de su movimiento: "Matar los amos y tomar la tierra" (54).

Estos dos conceptos que brindan la clave de varias revueltas en la época que nos ocupa son la expresión de una toma de conciencia revolucionaria sui generis. Dan buena cuenta de esta empresa radical, aunque rudimentaria, de descolonización que representan las sediciones de los esclavos. De hecho, el proyecto de matar a sus amos y tomar la tierra que les pertenecía ofrecía a la vez una connotación política y una connotación social.

A) - Connotación política primero: puede preguntarse, en efecto, si el concepto "tierra" no se aplicaba al mismo territorio en la intelección del esclavo. Tal interpretación no puede reputarse arbitraria o aventurada si se tiene en cuenta la aproximación muy empírica al mundo colonial que autorizaban las pocas luces del esclavo rural. Para éste último, apoderarse de la tierra de los amos equivalía inequivocadamente a hacerse dueño del país. Por cierto era una ilusión óptica. Pero este tipo de discurso

(53) Diario de Sesiones... 1836.

(54) AGI. Cuba, leg. n² 2.085, Comisión Militar Ejecutiva. Plaza de La Habana, Año de 1826. 
era común en el seno de las masas esclavas de todas las Antillas. Así es como el general Prim, gobernador de la isla de Puerto Rico, aseguraba que los objetivos de una conspiración de esclavos, que había sido delatada en Ponce, eran los siguientes:

Quemar las fincas, dirigirse a dicha población para saquearla e incendiarla, degollar a todos los blancos y quedar de este modo libres y pacíficos poseedores del territorio (55).

De manera muy idéntica, en la región de Trinidad de Cuba, los esclavos rurales confabulados con los de la ciudad pretendían "quedarse libres y hacerse dueños de la tierra» (56), lo que, a nuestro parecer, patentizaba la ambivalencia del término en la mente de dichos esclavos, ya que también en este caso en la estrategia de los conspiradores se trataba de adueñarse de la misma ciudad que era por excelencia el centro del poder opresor. Desde luego, la relación entre colonia y metrópoli no podía captarse del todo por los esclavos rebeldes, quienes nunca cuestionaron el régimen político español garante del orden colonial. Como acertó a decir Elías Entralgo, si una "compleja creencia en el derecho a la libertad" acompañaba aquellos alzamientos de esclavos, éstos «partían del supuesto que esa fuente jurídica estaba en la Metrópoli y el dique en la Factoría» (57).

B) - Connotacion social en segundo lugar: la fisionomía agraria de las revueltas de esclavos merece toda nuestra atención. Situados en las mismas condiciones no jurídicas sino socioeconómicas que los campesinos pobres o mejor aún los braceros y peones explotados por los terratenientes latifundistas, los esclavos no dejan de manifestar, como éstos últimos, su sed de tierra. Pero las rebeliones del esclavo rural no tenían únicamente por objeto la destrucción de la tenencia agraria vigente; se atacaban a los propios fundamentos de la sociedad colonial toda. Por ello, el esclavo rebelde no se puede identificar con el típico «rebelde primitivo" cuyas estrategias han sido analizadas con acierto por Eric J. Hobsbawm. En este mismo orden de ideas, cabe advertir cómo la reivindicación agraria que conformaba la sublevación de las dotaciones, en ciertos casos, iba mucho más lejos que la

(55) Proclama del Gobernador D. P. Prim, En Cayetano Coll y Toste, Historia de la esclavitud en Puerto Rico, San Juan 1977 pág. 189.

(56) ANC, Asuntos Políticos, leg. 39, no 46.

(57) EnTralgo, [20], pág. 20. 
de los cimarrones. Estos, como hemos visto, se hubieran contentado con vivir al margen del mundo colonial en el marco de una coexistencia pacífica. Sin duda éstos como aquéllos pretendían en sus pronunciamientos librarse de las faenas del ingenio o del cafetal. Pero, además de ello, los esclavos sublevados querían apoderarse de la tierra de sus amos, lo que significaba que entendían como legítima una rotunda transferencia de la riqueza en su beneficio (58). La idea imperante en los años 1840 era que los amos eran sus deudores. No cabe duda que este peregrino concepto fue propagado por los emisarios de las sectas abolicionistas radicadas en la vecina isla de Jamaica, o por los funcionarios de Su Majestad británica residentes en la de Cuba cuya comprobada filantropía se compaginaba con los intereses económicos de su nación. A este respecto, las inquietudes del ministro español, Martínez de la Rosa, no carecían de fundamento, quien públicamente declaraba: «Está en los intereses de la Ynglaterra concluir con nuestras Antillas, sean los que quieran los mediosm... (59).

En resumidas cuentas, las revueltas libertarias constituían desde el punto de vista a la vez sociopolítico y socioeconómico, una doble agresión contra la hegemonía de los hacendados esclavistas y contra las orientaciones de la producción agraria impuestas al territorio colonial por la metrópoli y el mercado internacional.

\section{Los libres a la ofensiva}

Al recrudecimiento de las rebeldías y cimarronadas de los esclavos corresponde una acérrima toma de conciencia de la gente de color libre en su conjunto: desde el punto de vista social el sistema esclavista hacía crisis al alcanzar su fase de mayor desarrollo económico. Algunos años después de la intentona de José Antonio Aponte, los pardos y morenos libres, como se decía, estaban ya persuadidos del potencial socioeconómico que formaban y de la legitimidad de sus aspiraciones a mejorar su estatuto jurídico, que mucho distaba de su situación social y económica. Con razón Francisco de Arango y Parreño, en su calidad de oráculo de la plantocracia cubana, había puesto de

(58) H. APTEKER, Las revueltas de los esclavos norteamericanos, México, 1969, pág. 5: el historiador señala esta misma tendencia en las revueltas en los Estados Unidos.

(59) Diario de sesiones. Sesión de 31 de enero de 1845, pág. 1.420. 
relieve, en su tiempo, la inconformidad permanente en que vivían los libres: apuntaba en su conocido Discurso sobre la agricultura de La Habana

La opinión pública..., el uniforme modo de pensar del mundo conocido los ha condenado a vivir en el abatimiento y en la dependencia del blanco y esto solo basta para que jamás se conformen con su suerte, para que estén siempre dispuestos a destruir el objeto a que atribuyen su envilecimiento (60).

Ahora bien, con el repentino auge de la economía de plantación a principios del siglo XIX y su corolario obligado, el ingente aumento de los esclavos se produjo una modificación sensible de la relación entre los distintos grupos étnicos y un empeoramiento súbito de la condición moral de la gente de color libre: «ocurre, escribe a este respecto Gerardo Brown Castillo, un fenómeno que escinde la homogeneidad horizontal hasta ese momento existente, con un proceso de creciente reducción del ámbito vital del negro y del pardo que, como grupo racial, había de sufrir un descenso en la estimación social del grupo dominante" (61).

En otros términos, el despegue azucarero originó una era de tensiones raciales que dio por acabada la anticuada convivencia, siendo sustituída por un patente racismo con ribetes de segregacionismo. Este cambio ético-social mucho afectó a los libres de color que, a duras penas, habían constituído una pequeña burguesía - al decir de José Luciano Franco- o al menos una clase ascendente de artesanos y comerciantes, en las áreas urbanas según el análisis de Pedro Deschamps Chapeaux (62). No debe perderse de vista, por otra parte, que la promoción económica y social de los libres en el siglo XIX era el objeto de los recelos de los miembros de los grupos dominantes. Hasta el insigne Padre Varela, que representó a la isla de Cuba en las Cortes de 18221823, no deja de lamentar que «estando los libres casi todos dedicados, a las artes así mecánicos como liberales,... había veinte de color para un artista blanco" (63).

En estas circunstancias dichos libres inician, al igual que en los demás países esclavistas del Caribe insular, una lucha por la

(60) ARANGo [25], tomo I, págs. 53-100.

(61) G. Brown Castillo, Cuba colonial, La Habana, 1952, pág. 26.

(62) El negro en la economía habanera del siglo XIX. La Habana, 1970, passim.

(63) "Memoria que demuestra la necesidad de extinguir la esclavitud de los negros en la isla de Cuba, atendiendo a los intereses de sus propietarios, por el Presbítero Don Félix de Varela, Diputado a Cortes". 
transformación de su estatuto exigiendo la total equiparación con los blancos como aparece en un manifiesto publicado en $\mathrm{La}$ Habana, en 1828, bajo el título de Justo sentimiento de pardos y morenos españoles de La Habana.

Pardos y morenos somos los que desempeñamos las artes mecánicas en el mayor grado de perfección, con admiración de los profesores de otras naciones ilustradas. Tenemos posesiones para vivir con nuestras familias, para nuestros talleres y para dar en arrendamiento indistintamente a los que carecen de ellas. Tenemos fincas rurales y siervos en los mismos términos que poseen estas propiedades los que componen la población entera el pueblo habano (64).

El contenido de las reivindicaciones igualitarias de los libres traducía una cumplida asimilación de las ideas nuevas que circulaban libre y lícitamente durante los dos períodos liberales en España a principios del siglo XIX en las que se había decretado la libertad de prensa, como no se ignora. Así pues, sólo con hojear las gacetas y los libros que versaban en temas políticos, los libres de color pudieron encontrar las herramientas ideológicas modernas que les hacía falta para sus luchas y que se avenían a sus anhelos democráticos. A este respecto, cabe citar, entre otros, el libro titulado el Catecismo de Doctrina Civil de Andrés de la Moya Lururiaga que fue muy leído y discutido en las tertulias a que acudían los libres. En dicho Catecismo se ponía en tela de juicio la servidumbre bajo todas sus formas, eran condenadas la trata y la esclavitud y ensalzada la igualdad original. La obra publicada, por primera vez en Cádiz, circuló mucho en La Habana, donde fue editada por segunda vez en 1813. Diez años después las autoridades coloniales se dieron cuenta de que el Catecismo se había convertido en el breviario de los libres cultos y que circulaba por toda la isla bajo la forma de manuscritos, lo que evidenciaba el papel que estaba desempeñando en la preparación política de todos (65).

En estas condiciones, superando los esfuerzos iniciales del

(64) Cabe señalar que dicho manifiesto mucho tenía que ver con otro famoso alegato titulado De la situation des gens de couleur aux Antilles Françaises (1823) que dio lugar al famoso caso Bissette. Este fue el líder de los libres de color en la isla de Martinica: éstos exigían "una legislación de acuerdo con el estado actual de la civilización".

(65) ANC, Asuntos Políticos, leg. 19, no 39: "Cuaderno que contiene el testimonio de varios papeles que corren agregados a la causa contra varias personas de color, por sospechas de infidencia" (10 de enero de 1822). 
precursor, el autodidacto José Antonio Aponte, pardos y morenos libres iban adquiriendo una genuina cultura política según la información que nos facilita el inquieto Padre Varela:

Se aumentan nuestros temores con la rápida ilustración que adquieren diariamente los libertos en el sistema representativo, pues la imprenta los instruye, aunque no se quiera, de sus derechos, que no son otros que los del hombre tan repetidos por todas partes, y les hace concebir deseos muy justos de ser tan felices como aquéllos a quienes la naturaleza sólo diferenció en el color (66).

Como era de esperarse los intentos de disfrutar de la soñada igualdad con los blancos se convirtieron a la sazón en actos revolucionarios. Del cúmulo de expedientes sobre casos de infidencia en que iban involucrados los libres se desprende que su actuación se centró en torno a dos estrategias:

1. El compromiso con los revolucionarios criollos blancos que, pese a la ambigüedad que conlleva, es un buen testimonio del grado de sensibilización de un sector importante de la gente de color a la cuestión de la independencia. Fueron bastante numerosos los pardos y morenos libres que participaron en la famosa conspiración de los Soles y Rayos de Bolivvar. Sin embargo, conviene advertir que al confabularse con los patriotas criollos, algunos libres —quizás los mulatos en primerísimo lugar- obsesionados por el único anhelo de promoción social de su clase, se distanciaron de la esperanza de los esclavos. Parece significativo al respecto que en la referida conspiración de los Soles y Rayos..., uno de los más destacados dirigentes locales, el mulato Andrés Manuel Sánchez, que fue compañero de armas del revolucionario Francisco Agüero Velazco, se opusiera a cualquier recurso a los esclavos para combatir a las tropas españolas (67).

2. A la inversa, la conjunción entre los libres y los esclavos proporcionó más facultades y mejor cohesión a la rebeldía de estos últimos. Su mero estatuto jurídico y su mejor preparación impelía a los libres a constituir el estado mayor de las rebeliones negras en la isla. El precavido ministro Martínez de la Rosa bien había captado esa disposición natural de aquéllos: «Es necesario

(66) Memoria ... [62].

(67) AGI, Ultramar, leg. 113, Puerto Príncipe 22 de febrero de 1826. Declaración voluntaria de Andrés Manuel Sánchez. 
evitar, advertía en un discurso, el contacto de los negros libres con los negros esclavos porque cada negro libre es, digámoslo así, una proclama viva de insurrección. No necesita hablar, no necesita más que presentarse y llevar estampado su color en el rostron (68).

No todo era, en rigor, solidaridad étnica. Se plasmaba en aquel entonces, el imprescindible frente social de lucha capaz de trastornar el sistema esclavista. Así es como, en nuestra opinión, se puede enfocar la conspiración de mucha amplitud fomentada en 1839 por el negro libre León Monzón, que era, nada menos que capitán en el Batallón de Morenos Leales de La Habana (69). En esta misma óptica, no debe olvidarse el papel determinante que desempeñaron las sociedades abolicionistas en el proceso de unificación de las luchas dirigidas por los libres y los esclavos. Se sabe que debidamente aleccionadas por dichas sociedades, varios libres cubanos, que incluso viajaban a los territorios británicos del Caribe, pudieron adquirir una preparación suficiente como para sustituir a los más avezados emisarios abolicionistas ingleses cuya conocida penetración ideológica en el seno de las masas esclavas se hacía más difícil cuando no improcedente por la activa vigilancia de las autoridades coloniales españoles. El vicecónsul de España en Kingston advertía:

No pudiendo introducir libremente sus emisarios, se valen de los mismos hijos de la Ysla para propagar sus principios, el imbuirles en los mismos sentimientos que han arruinado sus colonias, y facilitar por el mismo medio el que estas ideas se propaguen entre nosotros (70).

\section{CONCLUSIÓN}

No nos parece aventurado reiterar, a modo de conclusión, que por su contenido ideológico y por su programa libertario, las rebeldías negras han contribuido a la desestabilización del orden colonial esclavista en la isla de Cuba. Desde luego, para llegar a más concreciones sobre esta temática, seguimos estando necesitados de más informaciones mediante fuentes directas, lo que en

(68) Diario de Sesiones (1845), sesión lunes 27 de enero de 1845, pág. 1.389.

(69) ANC, Comisión Militar, leg. 23, n 1.

(70) AHN, Estado, leg. 8.057, carta del 3 de febrero de 1842: "Consulado de S.M.C. en Jamaica. El vice-cónsul encargado del Consulado, Carlos Duquesnay = Excmo. Sor Capitán General de la Ysla de Cuba...". 
el caso de la "gente sin historia" resulta ser casi imposible tratándose del período que venimos estudiando. Con todo, creemos que después de examinar este bloque empapado en tinieblas, que representa la resistencia colectiva de los pardos y morenos a la opresión esclavista, pueden distinguirse en plano cronológico dos etapas durante la primera mitad del siglo XIX - una de iniciación, otra de maduración- y tres niveles distintos en el proceso de puesta en obra de la misma, a lo largo de la isla.

Contemplando esas tres manifestaciones de rebeldía colectiva se nos ocurrió proponer una tipología, sin que pretendamos por tanto agotar las posibilidades de aproximación a este fenómeno plural. Permítasenos recordar al respecto que el objetivo real de los cimarrones fue en definitiva lograr lo que llamaremos una «independencia separada" formando comunidades de campesinos libres y viviendo según pautas sociales y leyes propias o bien patrones culturales genuinos. Así sucedió, en rigor, en los Blue Mountains en Jamaica o en la selva virgen guayanesa donde perviven hoy día auténticos descendientes de cimarrones.

Más radical fue el proyecto de las revueltas de los esclavos que sonaron con sustituir a sus amos en las haciendas cuando no en todo el territorio insular según el peregrino y único modelo que dio paso al llamado Estado negro de Haití. Mejor preparada y más sensible a la cuestión de las relaciones de fuerza entre la colonia y la Metrópoli, la gente de color libre cuya americanidad es obvio señalar, quiso aunar en su programa los insustituibles dogmas de libertad e igualdad y el nuevo culto a la independencia nacional al cual tributaban los criollos blancos... Así se explica, en nuestra opinión, la operación policiaca que al mediar los años 1840, llevó a cabo el entoncẹs capitán general O’Donnell para sofocar en la cuna lo que hasta hoy no se sabe si fue una conspiración general de la gente de color -la llamada conspiración de la Escalera-. Entre otras cosas O’Donnell declaraba:

No sólo se ha obtenido la ventaja de depurar la clase negra libre, toda en general contaminada, sino que el ejemplo y el escarmiento será saludable y enfrenará también los intentos de los blancos que deseen promover trastornos para llegar a conseguir la independencia de este país (71).

(71) AHN, Estado, leg. 8.039, n 16. Doc. $n^{0} 55$, "Contesta la Real Orden de 22 de abril relativa a proponer las medidas que se creen oportunas al sostenimiento del orden". 
En resumidas cuentas, las rebeliones negras de la primera mitad del siglo XIX que entrañaban componentes a la vez sociales y culturales constituyeron una amenaza aprovechada por el poder colonial para poner coto al desenvolvimiento de la insurgencia criolla. Había que esperar la segunda mitad del siglo para que triunfara en las filas del ejército mambí la idea defendida por Carlos Manuel de Céspedes: "Cuba libre es incompatible con Cuba esclavista». 